Gut, 1974, 15, 89-93

\title{
A controlled trial of heparin therapy in the coagulation defect of paracetamol-induced hepatic necrosis
}

\author{
B. G. GAZZARD, R. CLARK, V. BORIRAKCHANYAVAT, AND ROGER WILLIAMS \\ From the Liver Unit, King's College Hospital and Medical School, London
}

SUMMARY Treatment of the coagulation disturbances developing with hepatic damage following a paracetamol overdose was assessed in a controlled trial of 22 patients, one half being given heparin and fresh frozen plasma and the other fresh frozen plasma alone. No significant difference was observed either in the speed of correction of the coagulation defect or in the clinical outcome. Twothirds of the patients had evidence of disseminated intravascular coagulation, but despite the presence of a severe coagulation defect, significant bleeding occurred in only five patients. This may be because with paracetamol-induced hepatic necrosis both the coagulation defect (and possibly other features attributable to severe hepatic insufficiency) are of shorter duration than in hepatic necrosis due to causes such as viral hepatitis in which the liver damage may be a continuing process.

The severe coagulation defect in acute hepatic necrosis is usually attributed to a failure of synthesis of clotting factors. Intravascular coagulation may also occur (Rake, Shilkin, Flute, Lewis, Winch, and Williams, 1971), the increased consumption of clotting factors lowering further the levels of clotting factors already reduced by impairment of hepatic synthesis. To control this intravascular coagulation we have used heparin giving this at the same time as fresh frozen plasma to raise the level of clotting factors. The first four patients (three in grade IV hepatic coma) who were treated in this way, from soon after the first signs of liver damage and before the development of bleeding, survived with a rapid return of the coagulation abnormality to normal (Rake et al, 1971). Further experience with this regime in 20 patients with acute hepatic necrosis from a variety of causes showed that the incidence of severe haemorrhage requiring transfusion was $35 \%$, as compared with $63 \%$ in 19 patients seen during an earlier period (Clark, Rake, Flute, and Williams, 1973a).

The increasing numbers of patients with hepatic necrosis following a paracetamol overdose being referred to this Unit made it possible to set up a controlled trial of therapy in a group of patients with a single aetiology for their hepatic failure. This paper describes the results obtained in the first 22

Received for publication 1 November 1973. patients admitted to the trial who were randomly allocated to treatment with fresh frozen plasma alone, or with both fresh frozen plasma and heparin. Knowing that many factors in addition to the coagulation disturbance could affect survival, the merits of the two treatments were assessed mainly from the speed and degree of correction of the coagulation disturbance.

\section{Design of Trial}

Twenty-four consecutive patients with paracetamolinduced hepatic necrosis aged between 17 and 48 years were admitted to the trial, the sole criterion being a prothrombin time ratio (patient over control) of more than $2 \cdot 2$. Treatment for one group consisted of $300 \mathrm{ml}$ of fresh frozen plasma intravenously, a similar volume being given every six hours until the prothrombin time ratio had returned to 1.25 or less. If the initial prothrombin ratio was greater than 6.0 , the volume of fresh frozen plasma was increased to $600 \mathrm{ml}$ every six hours for the first 24 hours. The other group received in addition heparin, given intravenously by constant pump infusion so as to maintain a blood heparin equivalent of $0.5 \mathrm{mg} / 100 \mathrm{ml}$, as measured by protamine titration (O'Shea, Flute, and Pannell, 1971).

The platelet count, one-stage prothrombin time, partial thromboplastin time with kaolin, and the thrombin clotting time were measured daily using 


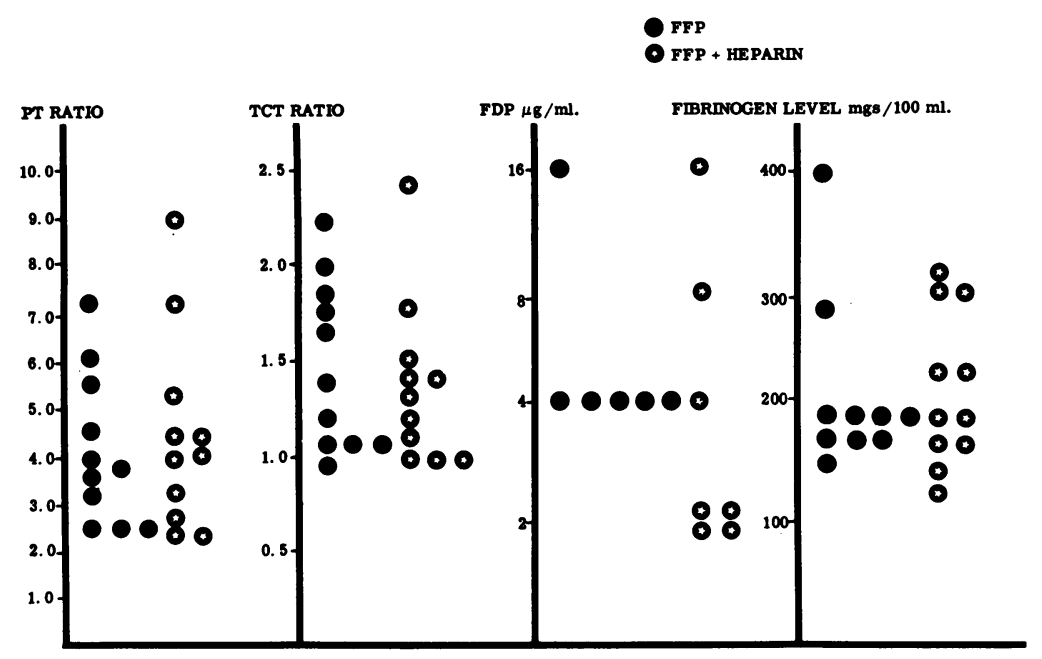

Fig 1 Results of coagulation tests in the 22 patients at the time of admission to the trial.

standard techniques (Hardisty and Ingram, 1965). Results were expressed as a ratio with a normal control. Daily estimations were also performed of the fibrinogen level as determined gravimetrically (Ingram, 1961) and of fibrin(ogen) degradation products in the serum by the tanned red cell haemagglutination inhibition technique (Merskey, Lalezari, and Johnson, 1969). The presence of fibrin strands in the plasma after protamine precipitation was assessed by the serial dilution protamine sulphate test (Gurewich and Hutchinson, 1971).

\section{Results}

Before the start of therapy, the two groups were comparable with respect to changes in prothrombin time, thrombin clotting time, fibrinogen levels, and levels of serum fibrin(ogen) degradation products, although for each of these measurements there was a considerable range of values in both groups (fig 1). Table I shows the coagulation data at the height of the illness in each patient, which was usually shortly after admission to the trial. The following were taken

\begin{tabular}{|c|c|c|c|c|c|}
\hline Case & PT Ratio & $\begin{array}{l}\text { Platelet Count } \\
(/ \mathrm{cmm})\end{array}$ & $\begin{array}{l}\text { Fibrinogen Level } \\
(\mathrm{mg} / 100 \mathrm{ml})\end{array}$ & $\begin{array}{l}\text { Fibrinogen Degradation } \\
\text { Products }(\mu \mathrm{g} / \mathrm{ml})\end{array}$ & $\begin{array}{l}\text { Serial Dilution } \\
\text { Protamine Sulphate } \\
\text { Test }\end{array}$ \\
\hline 1 & 3.9 & 150000 & 190 & 4 & + \\
\hline 2 & 3.0 & 70000 & 190 & 4 & + \\
\hline 3 & $5 \cdot 7$ & 200000 & 130 & 4 & + \\
\hline 4 & $3 \cdot 8$ & Ample & 190 & $<2$ & - \\
\hline 5 & $2 \cdot 3$ & 250000 & 290 & $<2$ & - \\
\hline 7 & $7 \cdot 5$ & 100000 & 170 & 4 & \\
\hline 8 & 2.9 & 90000 & 180 & 8 & + \\
\hline 9 & $6 \cdot 2$ & 240000 & 160 & 4 & + \\
\hline 10 & $3 \cdot 3$ & 180000 & 200 & 16 & + \\
\hline 11 & $4 \cdot 5$ & 173000 & 240 & $<2$ & - \\
\hline 12 & 2.9 & Ample & 200 & 8 & - \\
\hline 13 & $4 \cdot 3$ & 95000 & 140 & 2 & + \\
\hline 14 & $2 \cdot 5$ & 102000 & 250 & $<2$ & + \\
\hline 15 & $3 \cdot 8$ & 68000 & 180 & 8 & + \\
\hline 17 & $2 \cdot 2$ & 140000 & 80 & 16 & + \\
\hline 18 & $5 \cdot 0$ & Ample & 240 & $<2$ & + \\
\hline 19 & $3 \cdot 1$ & 85000 & 120 & 4 & + \\
\hline 20 & $9 \cdot 5$ & 115000 & 230 & 8 & + \\
\hline 21 & 4.9 & Ample & 190 & $<$ & - \\
\hline 22 & $7 \cdot 1$ & 70000 & 120 & 8 & + \\
\hline
\end{tabular}

Table I Coagulation tests at the height of the illness in 22 patients 


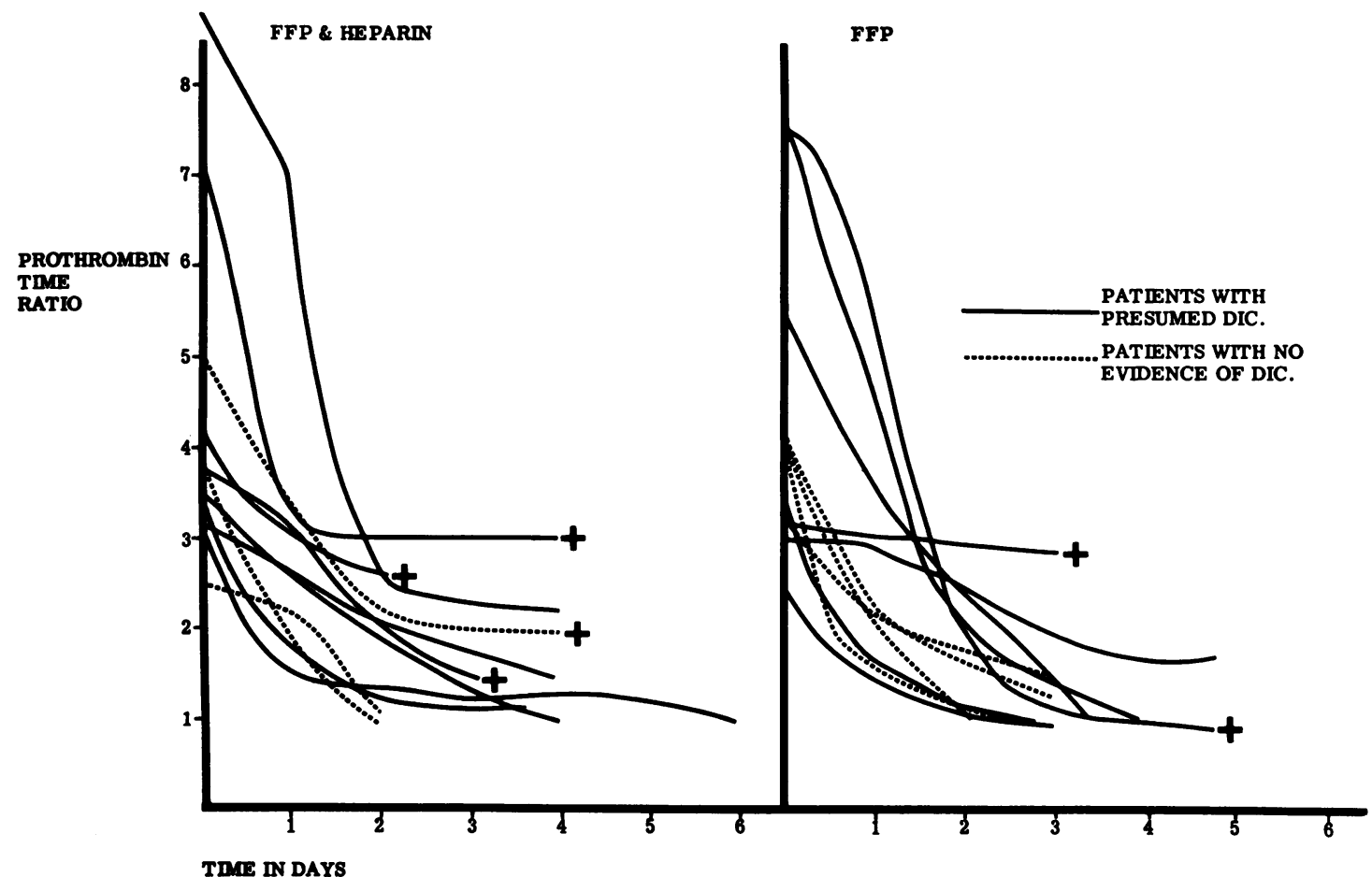

Fig 2 The fall in prothrombin time ratios with time in the two treatment groups

as evidence of intravascular coagulation: a fibrinogen level of less than $180 \mathrm{mg} / 100 \mathrm{ml}$ (normal in our laboratory $250 \mathrm{mg} / 100 \mathrm{ml}$ ); a positive serial dilution protamine sulphate test on at least two consecutive days; and fibrin(ogen) degradation products in concentrations of $4 \mu \mathrm{g} / \mathrm{ml}$ or more (normal in our laboratory $<2 \mu \mathrm{g} / \mathrm{ml}$ ). At least two of these abnormalities were present in a total of 14 patients, seven from each treatment group. Six of these patients also had a considerably reduced platelet count of less than $100000 / \mathrm{c} \mathrm{mm}$ and in seven the thrombin clotting time ratio was prolonged to greater than 1.5 . Despite the marked coagulation disturbance, only one patient had evidence of bleeding on admission, and this was minor.

Two patients developed an urticarial rash attributable to fresh frozen plasma and were withdrawn from the trial, leaving 11 in each group. Comparison of these showed no significant difference in the speed of correction of the coagulation disturbance, as judged by the rate of fall in prothrombin time (fig 2). The correction of the prothrombin time in the 14 patients considered to have intravascular coagulation was as rapid in those treated with fresh frozen plasma alone as when heparin was given in addition. The mean number of days taken to restore the prothrombin time to normal in those who survived was just over three days in both groups. The number of units of fresh frozen plasma given before the prothrombin time ratio had fallen to within 1.25 of normal was also comparable, averaging 17 in the heparin-treated group and 13 in the other.

In five patients significant bleeding occurred during the treatment periods, as evidenced by widespread petechiae or by a haematemesis and melaena. Four of these patients were in the combined treatment group and evidence of intravascular coagulation was present at the time of bleeding in four of the five patients.

OUTCOME AND RELATION TO LIVER DAMAGE Four patients, two in each group, were in deep hepatic coma, grade IV, as defined by Trey, Burns, and Saunders (1966) on admission, six other patients having less severe hepatic encephalopathy (table II). During the treatment periods, signs of liver failure progressed in a number of patients from both groups. Five patients in the heparin-treated group and two of those receiving fresh frozen plasma alone deteriorated to grade IV coma. Three from the former 


\begin{tabular}{|c|c|c|c|c|c|}
\hline Case & Age (Years) & Tablets Ingested (No.) & $\begin{array}{l}\text { Serum Bilirubin } \\
(\mathrm{mg} / 100 \mathrm{ml})\end{array}$ & $\begin{array}{l}\text { Aminotransferase } \\
(I U / 1)\end{array}$ & $\begin{array}{l}\text { Encephalopathy } \\
\text { Initial Grade }\end{array}$ \\
\hline 1 & 22 & 100 & $2 \cdot 2$ & $>250$ & 0 \\
\hline 2 & 38 & 100 & 6.7 & $>1000$ & 0 \\
\hline 3 & 48 & 30 & 11.0 & 500 & II \\
\hline 4 & 17 & 40 & $1 \cdot 2$ & $>250$ & 0 \\
\hline 5 & 22 & 50 & $4 \cdot 2$ & $>250$ & 0 \\
\hline 6 & 42 & $?$ & $2 \cdot 6$ & 2600 & 0 \\
\hline 7 & 30 & 70 & 9.0 & $>1000$ & IV \\
\hline 8 & 19 & 70 & 3.4 & $>1000$ & 0 \\
\hline 9 & 47 & $?$ & 20.9 & $>1250$ & II \\
\hline 10 & 29 & 50 & 4.8 & $>250$ & IV \\
\hline 11 & 19 & 45 & $3 \cdot 2$ & $>500$ & I \\
\hline 12 & 35 & 60 & 9.0 & $>1250$ & IV \\
\hline 13 & 24 & 30 & $8 \cdot 4$ & 1200 & III \\
\hline 14 & 29 & 100 & 3.8 & $>3000$ & 0 \\
\hline 15 & 36 & 70 & $15 \cdot 5$ & 1175 & 0 \\
\hline 16 & 26 & 100 & $9 \cdot 5$ & $>1200$ & II \\
\hline 17 & 22 & 100 & 5.0 & $>1250$ & I \\
\hline 18 & 22 & 50 & $1 \cdot 7$ & $>250$ & 0 \\
\hline 19 & 38 & 70 & $10 \cdot 0$ & $>1250$ & IV \\
\hline 20 & 27 & 59 & $15 \cdot 0$ & $>1250$ & 0 \\
\hline 21 & 24 & 74 & 5.0 & $>250$ & 0 \\
\hline 22 & 23 & 75 & $4 \cdot 8$ & $>250$ & 0 \\
\hline
\end{tabular}

Table II Clinical and biochemical data of the 22 patients ${ }^{1}$

${ }^{1}$ Nos. 1-11 were treated with fresh frozen plasma, nos. 12-22 were given heparin as well. Serum bilirubin and aspartate aminotransferase values are the maximum levels recorded.

and one from the latter group died, as did two others, one from each of the treatment groups who were already in grade IV coma on admission. Before death the prothrombin time ratio was $\mathbf{1 . 6}$ greater in all six patients, although this was less than at the start of treatment.

These six fatal cases had the most severe liver damage whatever criterion was used for assessment. Five had evidence of intravascular coagulation on admission, while the sixth developed a strongly positive serial dilution protamine sulphate test just before death. In general there was a close correlation between the occurrence of intravascular coagulation and the degree of liver damage. The maximum levels to which plasma bilirubin rose in the patients with intravascular coagulation were significantly higher ( $P<0.01$ by Student's ' $t$ ' test) than in those without.

\section{Discussion}

The use of heparin in addition to fresh frozen plasma appeared to confer no benefit over fresh frozen plasma alone in the patients in this trial. One possible cause for the difference between this finding and previous experience (Rake et al, 1971; Clark et al, 1973a) is that the two groups were not strictly comparable, as shown by the greater number in the heparin-treated group developing grade IV coma which is known to be associated with a poor prognosis. However, the two groups did appear to be similar at the time of presentation with respect to the severity of coagulation abnormality, but the number of cases was small and there was a considerable range of values for each of the coagulation tests carried out. Another and more likely explanation is that a severe bleeding diathesis is less common with paracetamol-induced hepatic necrosis than with other causes of fulminant hepatitis. In none of the present cases was bleeding the direct cause of death, whereas this accounted for $53 \%$ of the deaths in the 'control group' of Clark et al (1973a). The patients in that series who were treated intensively with heparin and fresh frozen plasma, as already mentioned, had a lower incidence of fatal bleeding, but this may have been because they included a greater proportion of cases due to paracetamol overdose.

Nevertheless, the lack of bleeding in the present cases is surprising in view of the severe coagulation defect present, as shown by considerable prolongation of the prothrombin time in most instances. This is in keeping with the other evidence of severe liver damage, ie, the presence of hepatic encephalopathy in half of the patients at some time during the illness. There was also evidence of intravascular coagulation in a significant percentage and the development of this is closely dependent on the severity of hepatic necrosis (Clark, Borirakchanyavat, Gazzard, Rake, Shilkin, Flute, and Williams, 1973b). However, the prothrombin time reverted to normal over a few days with both treatment schedules and it could be that the duration of the synthetic defect and of intravascular coagulation is too short for the development of a clinical bleeding disorder. The frequency with 
which intravascular coagulation was found in the present series is similar to that found in an earlier analysis of 39 cases of paracetamol-induced hepatic necrosis (Clark et al, 1973b). In that series an increased catabolic rate of fibrinogen was demonstrated in many of the patients.

It might be argued that the value of fresh frozen plasma in the treatment of the coagulation disturbance secondary to paracetamol-induced hepatic necrosis has also not been proved. The administration of fresh frozen plasma causes few side effects but its use can be followed by hypernatraemia if the renal excretion of sodium is inappropriately low (Wilkinson, Blendis, and Williams, 1973). Currently we are assessing the effects of fresh frozen plasma versus no specific treatment in a controlled trial with an 'escape' clause allowing treatment to be started if the prothrombin time ratio exceeds 7 .

In fulminant hepatic failure due to other causes, such as viral hepatitis or halothane anaesthesia, we continue to see not only a higher frequency of bleeding but also patients in whom the use of heparin and fresh frozen plasma together is followed by a remarkably rapid return of the coagulation abnormality towards normal. Intravascular coagulation may play a more important role in these instances in which there may be a continuing process of liver damage, rather than a single insult as in a paracetamol overdose. The occurrence of intravascular coagulation in acute hepatic failure from a variety of causes has also been shown by Hillenbrand, Parbhoo, Jedrychowski, and Sherlock (1973), but it may be very difficult to obtain controlled data for the value of heparin because of the multiplicity of factors which could affect the clinical course and final outcome. This has proved the case in non-hepatic situations where intravascular coagulation is known to occur. A controlled trial of heparin therapy for intravascular coagulation associated with septicaemia showed improvement in the coagulation defect but no change in the overall mortality (Corrigan and Gordon, 1970).

Miss Jean Dalrymple and Mrs Gillian Ash gave skilled technical assistance. We thank Professor P. T. Flute and Dr R. P. H. Thompson for their valuable advice. B.G.G. was supported by the King's College Hospital Voluntary Research Trust, and V.B. by the Anandha Mahidol Foundation, Thailand.

\section{References}

Clark, R., Rake, M. O., Flute, P. T., and Williams, R. (1973a). Coagulation abnormalities in acute liver failure: pathogenetic and therapeutic implications. Scand. J. Gastroent., 8, Suppl. 19, 63-70.

Clark, R., Borirakchanyavat, V., Gazzard, B. G., Rake, M. O., Shilkin, K. B., Flute, P. T., and Williams, R. (1973b). Disordered hemostasis in liver damage from paracetamol overdose. Gastroenterology, 65, 788-795.

Corrigan, J. J., Jr., and Jordan, C. M. (1970). Heparin therapy in septicemia with disseminated intravascular coagulation. New Engl. J. Med., 283, 778-782.

Gurewich, V., and Hutchinson, E. (1971). Detection of intravascular coagulation by serial-dilution protamine sulfate test. Ann. intern. Med., 75, 895-902.

Hardisty, R. M., and Ingram, G. I. C. (1965). Bleeding Disorders, p. 225. Blackwell, Oxford.

Hillenbrand, P., Parbhoo, S. P., Jedrychowski, A., and Sherlock, S. (1973). Significance of intravascular coagulation and fibrinolysis in acute hepatic failure. Scand. J. Gastroent., 8, Suppl. 19, 133-134.

Ingram, G. I. C. (1961). A suggested schedule for the rapid investigation of acute haemostatic failure. J. clin. Path., 14, 356-360.

Merskey, C., Lalezari, P., and Johnson, A. J. (1969). A rapid simple sensitive method for measuring fibrinolytic split products in human serum. Proc. Soc. exp. Biol. (N.Y.), 131, 871-875.

O'Shea, M. J., Flute, P. T., and Pannell, G. M. (1971). Laboratory control of heparin therapy. J. clin. Path., 24, 542-546.

Rake, M. O., Shilkin, K. B., Flute, P. T., Lewis, M. L., Winch, J., and Williams, R. (1971). Early and intensive therapy of intravascular coagulation in acute liver failure. Lancet, 2, 1215-1218.

Trey, C., Burns, D. G., and Saunders, S. J. (1966). Treatment of hepatic coma by exchange blood transfusion. New Engl. J. Med., 274, 473-481.

Wilkinson, S., Blendis, L., and Williams, R. (1973). Frequency and type of renal impairment and electrolyte disturbance in fulminant hepatic failure. (In preparation). 